\title{
MÉtodos De MANEJo DE Cyperus esculentus NA LAVOURA DE ARROZ IRRIGADO $^{1}$
}

\author{
Cyperus esculentus Handling Methods in Irrigated Rice
}

\author{
PANOZZO, L.E. ${ }^{2}$, AGOSTINETTO, D. ${ }^{3}$, GALON, L. ${ }^{4}$, MORAES, P.V.D. ${ }^{5}$, PINTO, J.J.O. ${ }^{3}$ e \\ NEVES, R. ${ }^{6}$
}

\begin{abstract}
RESUMO - As espécies da família Cyperaceae incluem-se entre as principais plantas daninhas que infestam as lavouras de arroz irrigado no Rio Grande do Sul. Objetivou-se com este trabalho avaliar o controle de Cyperus esculentus, a seletividade e a produtividade de grãos de arroz, cultivar Qualimax 1, em função de épocas de início da irrigação por inundação, épocas de aplicação e doses do herbicida penoxsulam. O experimento foi instalado em campo, no ano agrícola 2005/06. Utilizou-se o delineamento experimental de blocos ao acaso com parcelas subsubdivididas, com quatro repetições. Os tratamentos constaram de duas épocas de aplicação (precoce e tardia) do penoxsulam, três épocas de início da irrigação (1,15 e 30 dias após a aplicação dos tratamentos - DAT) e doses do herbicida $\left(0,24,36,48\right.$ e $\left.60 \mathrm{~g} \mathrm{ha}^{-1}\right)$. Observou-se que o penoxsulam apresentou seletividade à cultura do arroz irrigado, independentemente da associação dos tratamentos testados. A aplicação do penoxsulam, associado à entrada de água até 15 dias após a aplicação dos tratamentos, mostrou eficiente controle de C. esculentus. A maior produtividade foi obtida pela aplicação do penoxsulam em doses iguais ou superiores a $36 \mathrm{~g} \mathrm{ha}^{-1}$, independentemente da época de aplicação e quando a irrigação foi realizada nas épocas iniciais.
\end{abstract}

Palavras-chave: Oryza sativa, penoxsulam, irrigação da cultura, épocas de aplicação, cyperaceas.

\begin{abstract}
The Cyperaceae family include the most important weeds found in the state of Rio Grande do Sul rice fields. The objective of this work was to evaluate Cyperus esculentus control and rice $c v$. Qualimax 1 selectivity and grain yield in function of the irrigation starting times, application times and penoxsulam rates. The trial was set up under field conditions in the agricultural year of 2005/2006 and was arranged in a completely randomized block design with split plots and four replications. Treatments were in a factorial scheme $(2 \times 3 \times 5)$ and consisted of two herbicide application times (early and late), three irrigation starting times (1, 15 and 30 days aftertreatment), and herbicide rates $\left(0,24,36,48\right.$ and $\left.60 \mathrm{~g} \mathrm{ha}^{-1}\right)$. The herbicide penoxsulam showed selectivity to the rice culture regardless of the association between the evaluated treatments. The application of penoxsulam, combined with irrigation starting 15 days after herbicide application promoted efficient control of C. esculentus. Highest grain yield was obtained by applying penoxsulam at the rates of $36 \mathrm{~g} \mathrm{ha}^{-1}$ or above, regardless of the application time, and when early irrigation was carried out.
\end{abstract}

Keywords: Oryza sativa, penoxsulam, crop irrigation, application times, cyperaceas.

1 Recebido para publicação em 12.3.2008 e na forma revisada em 18.2.2009.

2 Engô-Agrọo , aluno do Programa de Pós-Graduação em Fitotecnia - Universidade Federal de Viçosa - DFT/UFV, Campus Universitário, 36570-000 Viçosa-MG, <lepanozzo@gmail.com>; ${ }^{3}$ Engoํ-Agr ${ }^{\circ}$, Dr., Prof. da Faculdade de Agronomia Eliseu Maciel - Universidade Federal de Pelotas - UFPel; ${ }^{4}$ Engoo-Agroo , D.Sc., Pós-Doutorado em Fitotecnia - DFT/UFV; ${ }^{5}$ Engo-Agro ${ }^{\circ}$, aluno do Programa de Pós-Graduação em Fitossanidade - UFPel; ${ }^{6}$ Eng $^{\circ}$-Agr ${ }^{0}$, M.Sc., Dow AgroSciences Indústria Ltda.

Planta Daninha, Viçosa-MG, v. 27, n. 1, p. 165-174, 2009 


\section{INTRODUÇÃO}

As plantas daninhas pertencentes ao gênero Cyperus incluem-se entre as principais espécies que infestam as lavouras de arroz irrigado do Rio Grande do Sul (RS) e Santa Catarina (SC). Os efeitos de suas interferências incluem competição por recursos limitantes (luz, água e nutrientes), aumento do custo de produção, acamamento das plantas da cultura, dificuldade de colheita, depreciação da qualidade do produto, hospedagem de pragas, redução do valor comercial das áreas (Lopez-Martinez et al., 1999) e liberação de aleloquímicos no meio (Dorst \& Doll, 1980). A espécie Cyperus esculentus é considerada a 16 $1{ }^{a}$ planta daninha mais importante no mundo (Defelice, 2002), devido à sua ampla adaptabilidade a muitos ambientes agrícolas, por ser perene e pela capacidade de se reproduzir sexuada e assexuadamente. A grande viabilidade dos tubérculos também contribui para a espécie formar grandes infestações e aumentar a sua importância (Negbi, 1992; Bariuan et al., 1999).

O grau de interferência das plantas daninhas na cultura do arroz irrigado varia em função da intensidade de infestação, dos cultivares utilizados e das práticas de manejo adotadas na lavoura, destacando-se a época do início da irrigação, época de aplicação e dose dos herbicidas pós-emergentes recomendados para a cultura.

O manejo da irrigação pode aumentar a atividade de herbicidas, possibilitando, dessa forma, ação mais eficiente sobre as plantas daninhas, como também impedir novos fluxos de plantas daninhas nas áreas inundadas, fator determinante para obtenção de altas produtividades de grãos (Fleck et al., 2004; Concenço et al., 2006a, b).

Outro fator relevante é o estádio de desenvolvimento das plantas daninhas no momento da aplicação do herbicida, o qual é de essencial importância para estabelecer a época ideal de controle, sem causar danos à cultura. Geralmente, os melhores resultados de controle são obtidos quando a aplicação é realizada em estádios precoces de desenvolvimento da planta daninha. A aplicação precoce do herbicida possibilita reduzir a dose e aumentar a eficácia de controle, desde que após a aplicação herbicida ocorra a imediata irrigação, para evitar a reinfestação (Concenço et al., 2006a, b; Agostinetto et al., 2007; Pinto et al., 2008).

Na prática, os produtores buscam utilizar herbicidas com atividade residual de solo, possibilitando retardar o início da irrigação, pois a inibição que seria exercida pela água é substituída pela ação do herbicida. No entanto, a extensão desse período depende do produto e dose utilizada, das características das espécies e niveis de infestação das plantas daninhas, e condições ambientais locais da lavoura (Andres $\&$ Machado, 2004; Agostinetto et al., 2007; Pinto et al., 2008).

O penoxsulam, pertencente ao grupo das triazolopirimidinas sulfonamidas, possui ação inibitória da enzima acetolactato sintase (ALS), básica para biogênese de aminoácidos essenciais de cadeia ramificada valina, leucina e isoleucina (Beyer et al., 1988; Concenço et al., 2006a). Essse herbicida controla amplo espectro de plantas daninhas (Jabusch \& Tjeerdema, 2005) e apresenta elevada seletividade à cultura do arroz, sendo registrado para aplicação em pós-emergência (Agrofit, 2008). Assim, a aplicação do penoxsulam em estádio precoce de desenvolvimento das plantas daninhas, associada à antecipação da época de início da irrigação, poderá permitir a redução da dose herbicida sem alterar o nivel de eficiência de controle das plantas daninhas, a seletividade e os componentes da produtividade da cultura.

Objetivou-se com o trabalho avaliar o controle de Cyperus esculentus, a seletividade e a produtividade de grãos de arroz, cultivar Qualimax 1, em função de épocas de início da irrigação por inundação, épocas de aplicação e doses do penoxsulam.

\section{MATERIAL E MÉTODOS}

O experimento foi instalado em campo, na Granja Quatro Irmãos, município de Rio Grande-RS, no ano agrícola 2005/06. O solo da área é classificado como Planossolo Hidromórfico Eutrófico solódico, pertencente à Unidade de Mapeamento Pelotas (Embrapa, 2006). A adubação foi feita de acordo com análise do solo, sendo utilizados $200 \mathrm{~kg} \mathrm{ha}^{-1}$ da formulação 5-20-20 na semeadura e $100 \mathrm{~kg} \mathrm{ha}^{-1}$ de $\mathrm{N}$ em cobertura, fracionados pela metade em aplicações no início do perfilhamento e na diferenciação do primórdio foliar, aos $36 \mathrm{e}$ 
aos 60 dias após a emergência do arroz (DAE), respectivamente.

$\mathrm{O}$ experimento foi instalado em sistema de cultivo mínimo, sendo o delineamento experimental de blocos ao acaso com parcelas subsubdivididas, com quatro repetições. Cada parcela foi composta por área de $225 \mathrm{~m}^{2}$; as subparcelas, por área de $75 \mathrm{~m}^{2}$; e as subsubparcelas (unidades experimentais), por área de $15 \mathrm{~m}^{2}$.

Os tratamentos constaram de épocas de aplicações do herbicida penoxsulam (precoce e tardia) (parcelas); épocas de início da irrigação (1, 15 e 30 dias após a aplicação dos tratamentos - DAT), sendo a água de irrigação mantida permanente até o momento da colheita da cultura (subparcelas); e doses do herbicida penoxsulam $\left(0,24,36,48\right.$ e $\left.60 \mathrm{~g} \mathrm{ha}^{-1}\right)$ (subsubparcelas).

O cultivar utilizado foi o Qualimax 1, semeado em 21/11/2005 na densidade de $150 \mathrm{~kg} \mathrm{ha}{ }^{-1}$, o que proporcionou estabelecimento de população aproximada de 400 plantas $\mathrm{m}^{-2}$, no espamento de $0,17 \mathrm{~m}$.

$\mathrm{Na}$ aplicação dos tratamentos herbicidas utilizou-se pulverizador costal pressurizado a $\mathrm{CO}_{2}$ com barra contendo quatro pontas de pulverização DG 110.02, trabalhando na pressão de $20 \mathrm{lb} \mathrm{pol}^{-2}$, aplicando um volume de calda de $150 \mathrm{~L} \mathrm{ha}^{-1}$. No momento da primeira aplicação (precoce) as plantas de arroz encontravam-se em estádio de 2-4 folhas, e as de C. esculentus, com 4-5 folhas. Na segunda aplicação (tardia), o arroz encontrava-se com quatro folhas e um afilho, e as plantas de C. esculentus, com 6-8 folhas. A população de C. esculentus foi de 161 plantas $\mathrm{m}^{-2}$.

As avaliações de fitotoxicidade foram realizadas aos 10 e 20 DAT, e as de controle da planta daninha, aos 10, 20, 30 DAT e no florescimento, para estádio precoce e tardio. Ambas as variáveis foram avaliadas pela atribuição visual de notas em escala percentual, em que a nota $0 \%$ significou nenhum efeito e a nota $100 \%$ representou morte completa das plantas.

A produtividade de grãos do arroz foi estimada pela colheita das plantas da área central das parcelas de $3 \mathrm{~m}^{2}(3 \times 1 \mathrm{~m})$, quando o teor de umidade dos grãos aproximou-se de $22 \%$. Após a pesagem dos grãos, foi determinada a umidade dos mesmos e corrigindo-se para $13 \%$ de umidade, sendo a produtividade expressa em $\mathrm{kg} \mathrm{ha}^{-1}$.

Os dados foram analisados quanto à sua homocedasticidade e, posteriormente, submetidos à análise da variância $(p \leq 0,05)$. A comparação das médias para os fatores época de início da irrigação e épocas de aplicação do penoxsulam foi efetuada pelo teste de Tukey ( $\mathrm{p} \leq 0,05)$ (Machado et al., 2002). Os efeitos de dose foram analisados por análise de regressão, utilizando-se modelos não-lineares (equações exponenciais) ( $\mathrm{p} \leq 0,05$ ou $\mathrm{p} \leq 0,10)$.

\section{RESULTADOS E DISCUSSÃO}

Quanto à fitotoxicidade, avaliada aos 10 DAT, houve interações entre os fatores testados (Tabela 1 e Figura 1). Na aplicação precoce, o atraso do início da irrigação aumentou a fitotoxicidade à cultura, porém a aplicação em estádio tardio não alterou a

Tabela 1 - Fitotoxicidade às plantas de arroz irrigado, cultivar Qualimax 1, aos 10 dias após a aplicação dos tratamentos (DAT), em função de épocas de início da irrigação, épocas de aplicação e doses do penoxsulam. Granja Quatro Irmãos, Rio Grande-RS, 2005/06

\begin{tabular}{|c|c|c|c|}
\hline Início da & \multirow{2}{*}{$\begin{array}{c}\text { Dose } \\
\text { irrigação }\end{array}$} & \multicolumn{2}{|c|}{ Época de aplicação } \\
\cline { 2 - 4 }$\left(\mathrm{g} \mathrm{ha}^{-1}\right)$ & Precoce & Tardio \\
\hline \multirow{4}{*}{ DAT $^{1 /}$} & 0 & $0 \mathrm{Aa}^{2}$ ' & $0 \mathrm{Aa}$ \\
\cline { 2 - 4 } & 24 & $0 \mathrm{Ba}$ & $0 \mathrm{Aa}$ \\
\cline { 2 - 4 } & 36 & $0 \mathrm{Ca}$ & $0 \mathrm{Aa}$ \\
\cline { 2 - 4 } & 48 & $0 \mathrm{Ca}$ & $0 \mathrm{Aa}$ \\
\cline { 2 - 4 } & 60 & $0 \mathrm{Ca}$ & $0 \mathrm{Aa}$ \\
\hline \multirow{4}{*}{ DAT } & 0 & $0 \mathrm{Aa}$ & $0 \mathrm{Aa}$ \\
\cline { 2 - 4 } & 24 & $1,0 \mathrm{Aa}$ & $0 \mathrm{Ab}$ \\
\cline { 2 - 4 } & 36 & $1,3 \mathrm{Ba}$ & $0 \mathrm{Ab}$ \\
\cline { 2 - 4 } & 48 & $1,5 \mathrm{Ba}$ & $0 \mathrm{Ab}$ \\
\cline { 2 - 4 } & 60 & $1,8 \mathrm{Ba}$ & $0,5 \mathrm{Ab}$ \\
\hline \multirow{4}{*}{30 DAT } & 0 & $0 \mathrm{Aa}$ & $0 \mathrm{Aa}$ \\
\cline { 2 - 4 } & 24 & $1,5 \mathrm{Aa}$ & $0 \mathrm{Ab}$ \\
\cline { 2 - 4 } & 36 & $2,0 \mathrm{Aa}$ & $0 \mathrm{Ab}$ \\
\cline { 2 - 4 } & 48 & $2,3 \mathrm{Aa}$ & $0,5 \mathrm{Ab}$ \\
\cline { 2 - 4 } & 60 & $2,5 \mathrm{Aa}$ & $0 \mathrm{Ab}$ \\
\hline
\end{tabular}

${ }^{1 /}$ Dias após aplicação dos tratamentos; ${ }^{2 /}$ Médias seguidas por mesma letra maiúscula, na coluna, comparando épocas de início de irrigação dentro de época de aplicação e dose, e seguidas por mesma letra minúscula, na linha, comparando época de aplicação dentro de época de início de irrigação e dose, não diferem entre si pelo teste de Tukey $(\mathrm{p} \leq 0,05)$.

Planta Daninha, Viçosa-MG, v. 27, n. 1, p. 165-174, 2009 

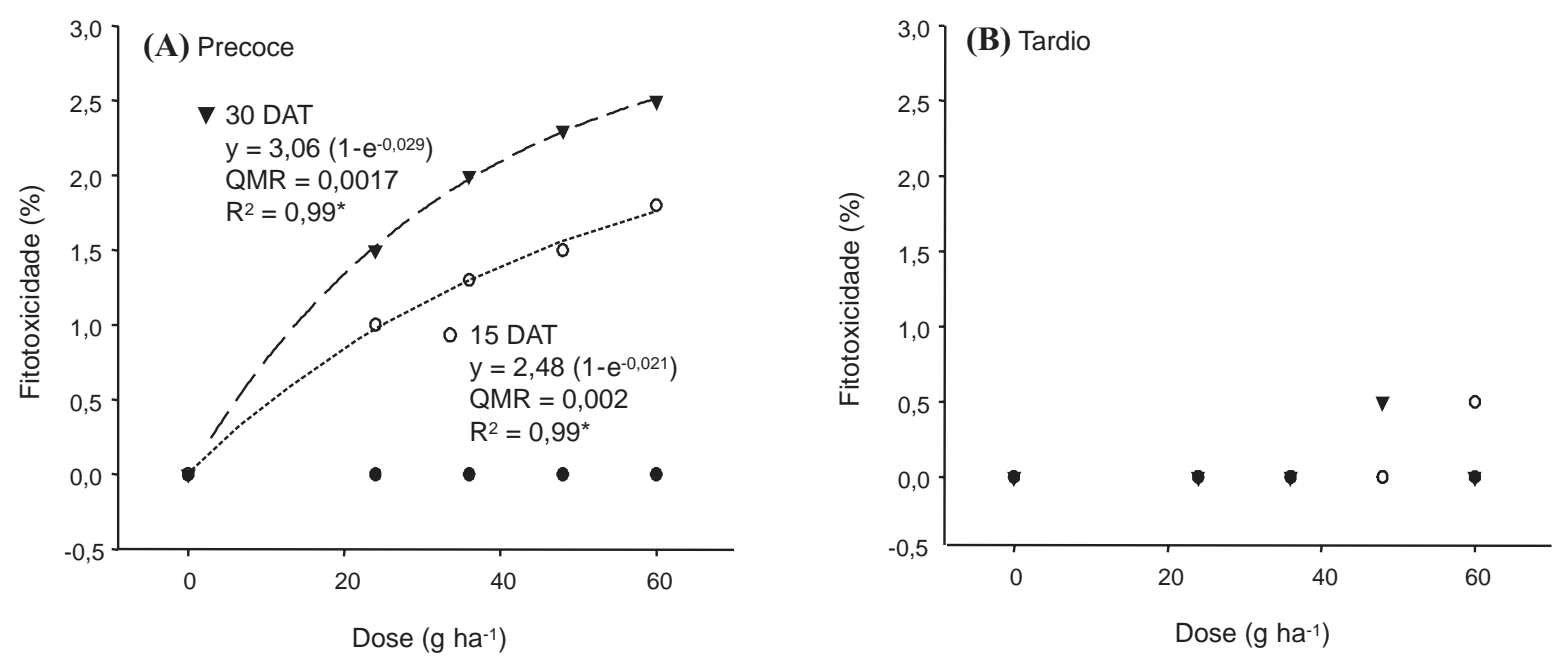

Figura 1 - Fitotoxicidade às plantas de arroz irrigado, cultivar Qualimax 1, aos 10 dias após a aplicação dos tratamentos (DAT), em função de épocas de início da irrigação (1 DAT, 15 DAT e 30 DAT), épocas de aplicação (precoce e tardia) e doses do penoxsulam. Granja Quatro Irmãos, Rio Grande-RS, 2005/06.

variável, independentemente da época de irrigação ou dose do herbicida (Tabela 1). A irrigação da lavoura aos 15 ou 30 DAT associada à aplicação precoce causou maior fitotoxicidade para a cultura, comparativamente à aplicação tardia.

Quando a aplicação foi realizada em estádio precoce (Figura 1A) e a irrigação iniciada aos 15 ou 30 DAT, o aumento da dose de herbicida incrementou a fitotoxicidade à cultura. $\mathrm{O}$ atraso de 14 dias no início da irrigação, de 15 para 30 DAT, elevou em $28 \%$ a fitotoxicidade inicial estimada pelo modelo utilizado. Quando a irrigação iniciou-se logo após a aplicação, não se verificou efeito fitotóxico do herbicida. Quando a aplicação foi realizada em estádio tardio (Figura 1B), não se obteve ajuste dos dados ao modelo estatístico. Na segunda época de avaliação de fitotoxicidade (20 DAT), não foi observada diferença significativa dos dados (dados não apresentados).

Os valores observados para a fitotoxicidade permitem inferir que o herbicida penoxsulam apresenta elevada seletividade ao cultivar Qualimax 1. Outros estudos também demonstraram que o herbicida penoxsulam é seletivo ao arroz irrigado (Concenço et al., 2006b; Pinto et al., 2008), corroborando com os dados observados neste experimento.

Para controle de C. esculentus, verificouse interação dos fatores (Tabela 2 e Figuras 2 e 3). A antecipação do início da irrigação, quando a aplicação do penoxsulam foi realizada em estádio precoce de desenvolvimento da planta daninha, em geral, aumentou a eficiência de controle de $C$. esculentus para todas as doses do herbicida e épocas de avaliação (Tabela 2). Esse resultado pode ser consequência do processo conhecido como autocalagem do solo após o início da inundação no arroz irrigado. Esse manejo causa redução do solo e, em consequência, aumento do $\mathrm{pH}$, incrementando assim a disponibilidade do herbicida para ser absorvido pelas plantas daninhas. Quando a aplicação do herbicida foi realizada em estádio tardio, em geral, para todas as doses e épocas de avaliação, a época de início da irrigação não modificou a eficiência de controle de C. esculentus.

A aplicação em estádio precoce de desenvolvimento, seguida de irrigação, aumentou a eficiência de controle de $C$. esculentus comparativamente à aplicação tardia, na avaliação realizada aos 20 DAT (Tabela 2). Contudo, nas demais épocas de avaliação, para todas as épocas de início da irrigação ou doses do herbicida, em geral, não se verificaram diferenças entre épocas de aplicação do penoxsulam. Esses resultados podem ser decorrentes do estádio com que as plantas daninhas foram controladas, visto que plantas jovens são normalmente mais suscetiveis à ação de 
herbicida, mas, à medida que o herbicida vai tendo seu efeito, essa diferença diminui.

O fator dose do penoxsulam, em função dos fatores época de início de irrigação e de aplicação, em relação ao controle de C. esculentus, demonstrou bom ajuste dos dados ao modelo, com $R^{2}$ de 0,99 e baixos valores do QMR (Figuras 2 e 3).

A antecipação do início da irrigação por inundação, em todas as épocas de avaliação, reduziu a dose do penoxsulam necessária para obtenção de controle eficiente de C. esculentus, independentemente da época de aplicação, em todas as avaliações, (Figuras 2 e 3 ). Considerando as duas últimas épocas de avaliação, observou-se que doses iguais ou superiores a $36 \mathrm{~g} \mathrm{ha}^{-1}$ do penoxsulam, quando a irrigação foi iniciada até 15 DAT, apresentaram controle eficiente de $C$. esculentus. Assim, o orizicultor poderá atrasar até 15 dias o início da irrigação do arroz, diminuindo o volume de água a ser utilizado e causando menores danos ao ambiente, sem ocorrer perdas pela competição com as plantas daninhas.

A comparação entre épocas de irrigação para a aplicação precoce, tendo por base os valores exponenciais do modelo, demonstrou que a antecipação da irrigação para 1 DAT, na média das quatro avaliações, apresentou valores 5,3 e 6,5 vezes menores, comparativamente, do que os observados quando a irrigação iniciou-se aos 15 e 30 DAT, respectivamente. A mesma comparação para aplicação tardia demonstrou valores 1,8 e 2,2 vezes menores para os inícios de irrigação aos 15 e 30 DAT, respectivamente. A maior inclinação das curvas do modelo demonstrou que menores doses dos herbicidas são necessárias para obtenção de controle equivalente. Comparando as épocas de aplicação, na média das épocas de início da irrigação, verificou-se que a aplicação precoce reduziu em $39 \%$ a dose herbicida necessária para obtenção de controle equivalente à aplicação tardia.

Tabela 2 - Porcentagem de controle de Cyperus esculentus na cultura do arroz irrigado, em função de épocas de início de irrigação, épocas de aplicação e doses do penoxsulam. Granja Quatro Irmãos, Rio Grande-RS, 2005/06

\begin{tabular}{|c|c|c|c|c|c|c|c|c|c|}
\hline \multirow{3}{*}{$\begin{array}{l}\text { Início da } \\
\text { irrigação }\end{array}$} & \multirow{3}{*}{$\begin{array}{c}\text { Dose } \\
\left(\mathrm{g} \mathrm{ha}^{-1}\right)\end{array}$} & \multicolumn{8}{|c|}{ Época de aplicação } \\
\hline & & Precoce & Tardio & Precoce & Tardio & Precoce & Tardio & \multirow{2}{*}{$\begin{array}{c}\text { Precoce } \\
81 \text { DAT }\end{array}$} & Tardio \\
\hline & & \multicolumn{2}{|c|}{$10 \mathrm{DAT}^{1 /}$} & \multicolumn{2}{|c|}{20 DAT } & \multicolumn{2}{|c|}{30 DAT } & & 65 DAT \\
\hline \multirow{5}{*}{$1 \mathrm{DAT}$} & 0 & $0 \mathrm{Aa}^{2 /}$ & $0 \mathrm{Aa}$ & $0 \mathrm{Aa}$ & $0 \mathrm{Aa}$ & $0 \mathrm{Aa}$ & $0 \mathrm{Aa}$ & $0 \mathrm{Aa}$ & $0 \mathrm{Aa}$ \\
\hline & 24 & $84 \mathrm{Aa}$ & $75 \mathrm{Aa}$ & $100 \mathrm{Aa}$ & $78 \mathrm{Ab}$ & $100 \mathrm{Aa}$ & $92 \mathrm{Ab}$ & $99 \mathrm{Aa}$ & $94 \mathrm{Aa}$ \\
\hline & 36 & $93 \mathrm{Aa}$ & $73 \mathrm{Ab}$ & $100 \mathrm{Aa}$ & $79 \mathrm{Ab}$ & $100 \mathrm{Aa}$ & $93 \mathrm{Aa}$ & $100 \mathrm{Aa}$ & $96 \mathrm{Aa}$ \\
\hline & 48 & $95 \mathrm{Aa}$ & $78 \mathrm{Aa}$ & $100 \mathrm{Aa}$ & $84 \mathrm{Ab}$ & $100 \mathrm{Aa}$ & $95 \mathrm{Aa}$ & $100 \mathrm{Aa}$ & $98 \mathrm{Aa}$ \\
\hline & 60 & $96 \mathrm{Aa}$ & $83 \mathrm{Aa}$ & $100 \mathrm{Aa}$ & $85 \mathrm{Ab}$ & $100 \mathrm{Aa}$ & $96 \mathrm{Aa}$ & $100 \mathrm{Aa}$ & $99 \mathrm{Aa}$ \\
\hline \multirow{5}{*}{$15 \mathrm{DAT}$} & 0 & $0 \mathrm{Aa}$ & $0 \mathrm{Aa}$ & $0 \mathrm{Aa}$ & $0 \mathrm{Aa}$ & $0 \mathrm{Aa}$ & $0 \mathrm{Aa}$ & $0 \mathrm{Aa}$ & $0 \mathrm{Aa}$ \\
\hline & 24 & $51 \mathrm{Ba}$ & $65 \mathrm{Aa}$ & $68 \mathrm{Ba}$ & $75 \mathrm{ABa}$ & $78 \mathrm{Ba}$ & $79 \mathrm{Ba}$ & $93 \mathrm{Aa}$ & $86 \mathrm{Bb}$ \\
\hline & 36 & $67 \mathrm{Ba}$ & $71 \mathrm{Aa}$ & $78 \mathrm{Ba}$ & $83 \mathrm{Aa}$ & $95 \mathrm{Aa}$ & $90 \mathrm{ABa}$ & $98 \mathrm{Aa}$ & $96 \mathrm{Aa}$ \\
\hline & 48 & $70 \mathrm{Ba}$ & $73 \mathrm{Aa}$ & $87 \mathrm{ABa}$ & $85 \mathrm{Aa}$ & $98 \mathrm{ABa}$ & $90 \mathrm{ABb}$ & $99 \mathrm{Aa}$ & $96 \mathrm{Aa}$ \\
\hline & 60 & $79 \mathrm{Aa}$ & $78 \mathrm{Aa}$ & $94 \mathrm{ABa}$ & $91 \mathrm{Aa}$ & $99 \mathrm{Aa}$ & $94 \mathrm{Aa}$ & $100 \mathrm{Aa}$ & $99 \mathrm{Aa}$ \\
\hline \multirow{5}{*}{$30 \mathrm{DAT}$} & 0 & $0 \mathrm{Aa}$ & $0 \mathrm{Aa}$ & $0 \mathrm{Aa}$ & $0 \mathrm{Aa}$ & $0 \mathrm{Aa}$ & $0 \mathrm{Aa}$ & $0 \mathrm{Aa}$ & $0 \mathrm{Aa}$ \\
\hline & 24 & $52 \mathrm{Ba}$ & $62 \mathrm{Aa}$ & $55 \mathrm{Ba}$ & $63 \mathrm{Ba}$ & $70 \mathrm{Ba}$ & $70 \mathrm{Ca}$ & $80 \mathrm{Ba}$ & $77 \mathrm{Ca}$ \\
\hline & 36 & $72 \mathrm{Ba}$ & $74 \mathrm{Aa}$ & $75 \mathrm{Ba}$ & $73 \mathrm{Aa}$ & $85 \mathrm{Ba}$ & $84 \mathrm{Ba}$ & $83 \mathrm{Ba}$ & $87 \mathrm{Ba}$ \\
\hline & 48 & $75 \mathrm{Aa}$ & $79 \mathrm{Aa}$ & $81 \mathrm{Ba}$ & $78 \mathrm{Aa}$ & $90 \mathrm{Ba}$ & $88 \mathrm{Aa}$ & $92 \mathrm{Ba}$ & $92 \mathrm{Aa}$ \\
\hline & 60 & $78 \mathrm{Aa}$ & $79 \mathrm{Aa}$ & $84 \mathrm{Ba}$ & $82 \mathrm{Aa}$ & $92 \mathrm{Aa}$ & $90 \mathrm{Aa}$ & $93 \mathrm{Aa}$ & $94 \mathrm{Aa}$ \\
\hline
\end{tabular}

1/ Dias após aplicação dos tratamentos; ²/ Médias seguidas por mesma letra maiúscula, na coluna, em cada época de aplicação, comparando épocas de início de irrigação dentro de dose, e seguidas por mesma letra minúscula, na linha, comparando época de aplicação dentro de dose herbicida e épocas de início da irrigação, não diferem entre si pelo teste de Tukey $(\mathrm{p} \leq 0,05)$. 

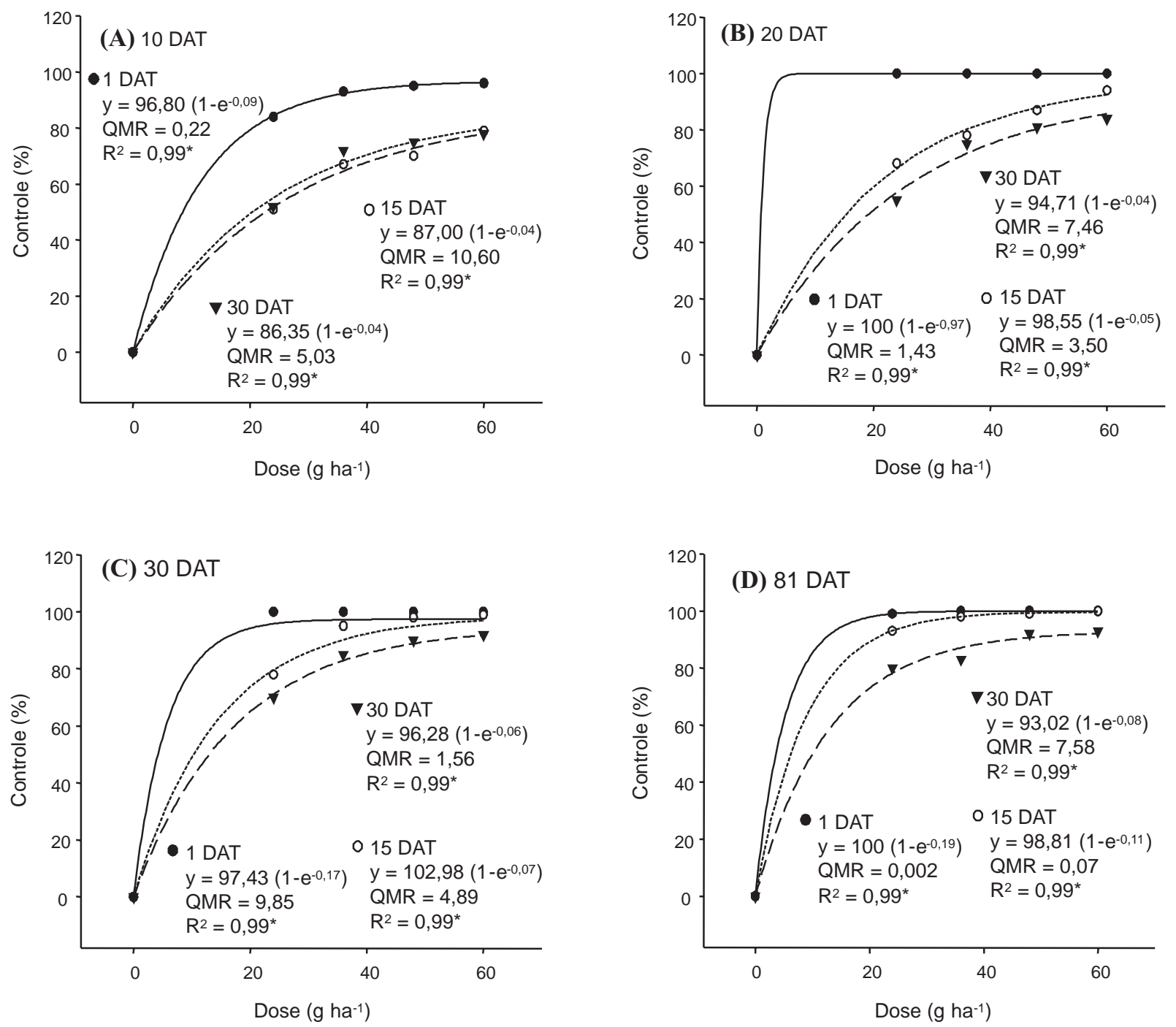

$\mathrm{R}^{2}$ : coeficiente de determinação; QMR: quadrado médio do resíduo; ${ }^{*}$ significativo a $5 \%$ de probabilidade.

Figura 2 - Controle de Cyperus esculentus na cultura do arroz irrigado em função das épocas de início da irrigação (1 DAT, 15 DAT e 30 DAT), doses do penoxsulam e época de aplicação precoce. Granja Quatro Irmãos, Rio Grande-RS, 2005/06.

Considerando que a antecipação da irrigação na cultura do arroz auxilia no manejo das plantas daninhas e serve como método preventivo, impedindo a emergência de novos fluxos de plantas (Fleck et al., 2004; Pinto et al., 2008), a associação do manejo da água com herbicidas que apresentam poder residual poderá aumentar a eficiência de controle ou permitir a redução da dose do herbicida. Nesse sentido, Concenço et al. (2006a) observaram que o penoxsulam proporciona controle de aproximadamente $97 \%$ para Cyperus spp., mesmo com o uso da metade da dose recomendada e associado com a irrigação tardia da lavoura.

Para a variável produtividade de grãos, verificou-se interação entre épocas de início de irrigação, dose e épocas de aplicação do penoxsulam (Tabela 3 e Figura 4). A influência de épocas de aplicação do herbicida na produtividade da cultura do arroz demonstrou, em geral, não haver diferença entre a aplicação precoce e a tardia do herbicida, independentemente da época de início da irrigação e das doses testadas (Tabela 3). Esses resultados podem decorrer do curto intervalo de tempo entre as duas épocas de aplicação. 

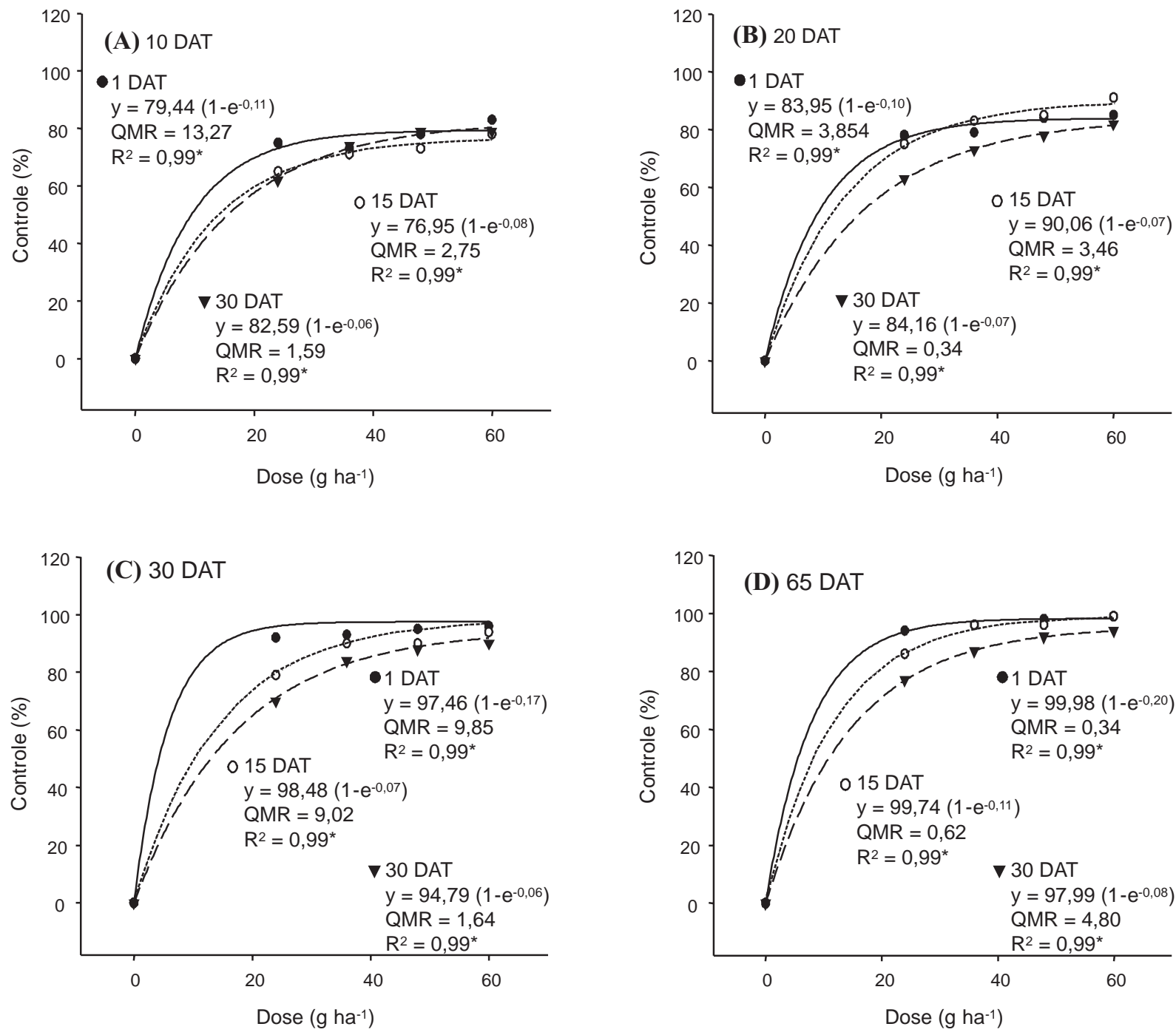

$\mathrm{R}^{2}$ : coeficiente de determinação; QMR: quadrado médio do resíduo; * significativo a $5 \%$ de probabilidade.

Figura 3 - Controle de Cyperus esculentus na cultura do arroz irrigado em função de épocas de início da irrigação (1 DAT, 15 DAT e 30 DAT), doses do penoxsulam e época de aplicação tardia. Granja Quatro Irmãos, Rio Grande-RS, 2005/06.

O atraso no início da irrigação por inundação reduziu a produtividade de grãos da cultura quando a aplicação foi realizada no estádio tardio de desenvolvimento, para todas as doses do herbicida testadas (Tabela 3). As unidades experimentais que foram inundadas em 1 DAT tiveram resultados absolutos superiores de produtividade de grãos, em ambas as épocas de aplicação e em todas as doses do herbicida. Na média de todas as doses do herbicida, a antecipação em 14 e 29 dias no início da irrigação, em relação à primeira época de irrigação, aumentou a produtividade de grãos, respectivamente, em cerca de 17 e $19 \%$ para a aplicação precoce e em 10 e $42 \%$ para a aplicação tardia.

A produtividade de grãos da cultura normalmente é reduzida com o atraso da irrigação além do período recomendado, de 15 a 30 dias após a emergência (Gomes et al., 1999), ou com a redução das doses dos herbicidas residuais (Concenço et al., 2006a; Pinto et al., 2008). Resultados demonstram redução de até $20 \%$ na produtividade de grãos do arroz em função do atraso da irrigação de 20 para $35 \mathrm{DAE}$ (Andres et al., 2007; Pinto et al., 2008). Nesse 
mesmo sentido, Ramirez et al. (2007) verificaram que a produtividade de grãos de arroz diminui em média $1.000 \mathrm{~kg}$ a cada 10 dias de atraso do início da irrigação na lavoura de arroz.

Tabela 3 - Produtividade de grãos de arroz irrigado $\left(\mathrm{kg} \mathrm{ha}^{-1}\right)$, cultivar Qualimax 1, em função de épocas de início da irrigação, épocas de aplicação e doses do penoxsulam. Granja Quatro Irmãos, Rio Grande-RS, 2005/06

\begin{tabular}{|c|c|c|c|}
\hline \multirow{2}{*}{$\begin{array}{c}\text { Dose } \\
\left(\mathrm{g} \mathrm{ha}^{-1}\right)\end{array}$} & \multicolumn{3}{|c|}{ Época de irrigação } \\
\cline { 2 - 4 } & $1 \mathrm{DAT}$ & $15 \mathrm{DAT}$ & $30 \mathrm{DAT}$ \\
\hline \multicolumn{4}{|c|}{ Precoce } \\
\hline 0 & $7.475 \mathrm{Aa}^{1 /}$ & $3.706 \mathrm{Ab}$ & $3.431 \mathrm{Ab}$ \\
\hline 24 & $8.289 \mathrm{Aa}$ & $8.015 \mathrm{Aa}$ & $7.093 \mathrm{Aa}$ \\
\hline 36 & $9.678 \mathrm{Aa}$ & $8.461 \mathrm{Aa}$ & $9.195 \mathrm{Aa}$ \\
\hline 48 & $9.751 \mathrm{Aa}$ & $9.400 \mathrm{Aa}$ & $8.695 \mathrm{Aa}$ \\
\hline 60 & $9.107 \mathrm{Aa}$ & $8.456 \mathrm{Aa}$ & $8.945 \mathrm{Aa}$ \\
\hline \multicolumn{5}{|c|}{ Tardio } \\
\hline 0 & $4.431 \mathrm{Ba}$ & $3.585 \mathrm{Aab}$ & $2.105 \mathrm{Ab}$ \\
\hline 24 & $8.659 \mathrm{Aa}$ & $8.027 \mathrm{Aa}$ & $6.022 \mathrm{Ab}$ \\
\hline 36 & $8.900 \mathrm{Aa}$ & $8.672 \mathrm{Aa}$ & $6.055 \mathrm{Bb}$ \\
\hline 48 & $8.997 \mathrm{Aa}$ & $7.583 \mathrm{Bab}$ & $6.847 \mathrm{Bb}$ \\
\hline 60 & $9.872 \mathrm{Aa}$ & $9.136 \mathrm{Aab}$ & $7.687 \mathrm{Ab}$ \\
\hline
\end{tabular}

1/ Médias seguidas por mesmas letras maiúsculas na coluna, comparando épocas de aplicação dentro de época de início da irrigação e dose, e minúsculas na linha, comparando época de início da irrigação dentro de época de aplicação e dose, não diferem entre si pelo teste de Tukey $(\mathrm{p} \leq 0,05)$

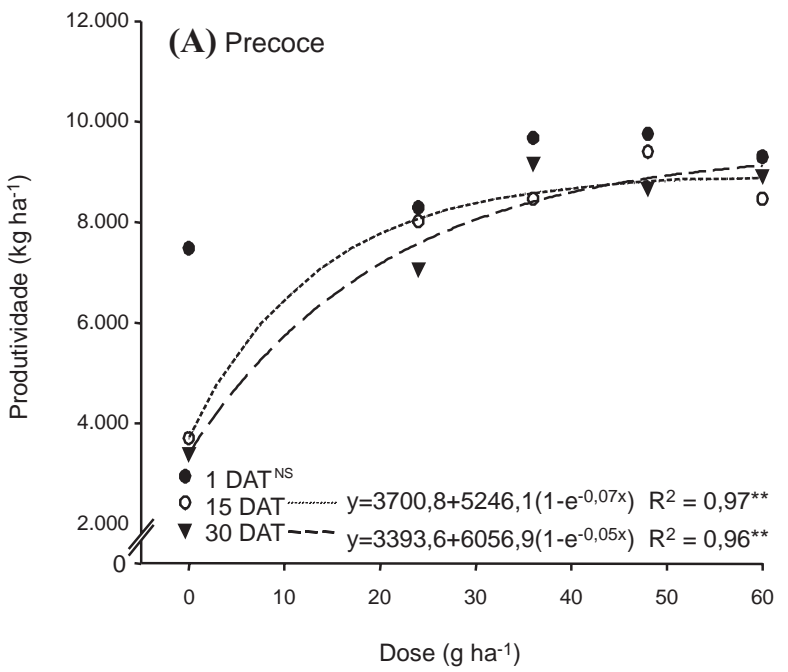

Em pesquisas realizadas com competição de $C$. esculentus na cultura do arroz, constataram-se reduções de aproximadamente $20 \%$ na produtividade de grãos, representando em média uma perda de 17 sacas ha-1 ${ }^{-1}$ Erasmo et al., 2003). Populações de 40 plantas $\mathrm{m}^{-2}$ de C. esculentus convivendo com a cultura de arroz irrigado até a colheita ocasionaram redução na produtividade de grãos na ordem de $39 \%$ (Alcântara, 1999).

A antecipação do início da irrigação para 1, 10 ou 20 dias após a aplicação dos tratamentos herbicidas aumentou a produtividade de grãos de arroz (Galon et al., 2007). Em estudo que avaliou os efeitos de épocas de início de irrigação e dose do herbicida penoxsulam, foi verificado que o atraso em 10 dias do início da irrigação após a aplicação deste herbicida reduziu em média $41 \%$ a produtividade de grãos de arroz (Pinto et al., 2008). De modo similar, Agostinetto et al. (2007) obtiveram incremento na produtividade de grãos de arroz quando o início da irrigação foi realizado aos 1 DAT, comparativamente às tardias 10 e 20 DAT.

$\mathrm{O}$ aumento das doses dos herbicidas incrementou a produtividade de grãos, tendendo a estabilizar nas doses superiores a $36 \mathrm{~g} \mathrm{ha}^{-1}$, independentemente da época de aplicação e quando a irrigação iniciou-se em período de até 15 DAT (Figura 4). Esses resultados podem

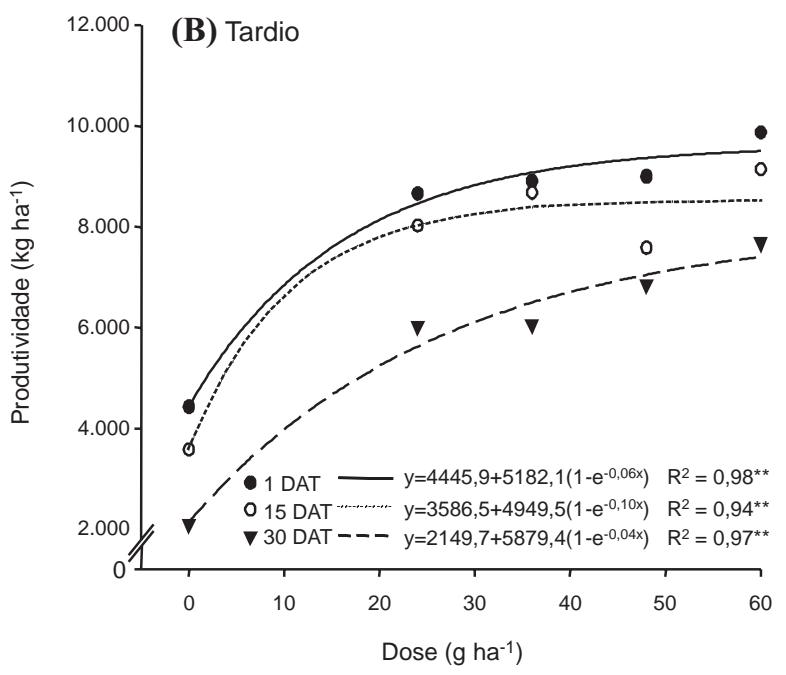

$\mathrm{R}^{2}$ : coeficiente de determinação; ** significativo a $10 \%$ de probabilidade; NS não-significativo.

Figura 4 - Produtividade de grãos do cultivar de arroz irrigado Qualimax 1, em função de épocas de início da irrigação (1 DAT, 15 DAT e 30 DAT), épocas de aplicação (precoce e tardia) e doses do penoxsulam. Granja Quatro Irmãos, Rio Grande-RS, 2005/06. 
decorrer da maior eficiência de controle das plantas daninhas obtidas nas doses maiores do herbicida.

O penoxsulam apresentou seletividade ao arroz irrigado, independente da época de início da irrigação, época de aplicação ou doses desse herbicida. O início da irrigação por inundação até 15 dias após a aplicação dos tratamentos, independentemente da época de aplicação do penoxsulam, apresentou eficiente controle de C. esculentus, sendo possivel reduzir a dose do herbicida para $36 \mathrm{~g} \mathrm{ha}^{-1}$. A maior produtividade de grãos da cultura foi obtida quando se aplicou o penoxsulam nas doses iguais ou superiores a $36 \mathrm{~g} \mathrm{ha}^{-1}$, independentemente da época de aplicação e quando a irrigação foi realizada nas épocas iniciais.

\section{AGRADECIMENTOS}

À DowAgroSciences, pela bolsa de estudos concedida, e à Granja Quatro Irmãos, por disponibilizar a área para realização do experimento.

\section{LITERATURA CITADA}

AGOSTINETTO, D. et al. Interferência de capim-arroz (Echinochloa spp.) na cultura do arroz irrigado (Oryza sativa) em função da época de irrigação. Planta Daninha, v. 25, n.4, p. $697-707,2007$.

\section{SISTEMA DE AGROTÓXICOS FITOSSANITÁRIOS -}

AGROFIT. Disponível em: <http://extranet.agricultura.gov.br; agrofit $>$. Acesso em: 10 jan. 2008.

ALCÂNTARA, E. N. Controle de plantas daninhas na cultura do arroz. Inf. Agropec., v. 14, n. 161, p. 40-44, 1999.

ANDRES, A. et al. Desempenho do cultivar de arroz BRS Pelota e controle de capim-arroz (Echinochloa spp.) submetidos a quatro épocas de entrada de água após aplicação de doses reduzidas de herbicidas. Planta Daninha, v. 25, n.4, p. 859-867, 2007

ANDRES, A.; MACHADO, S. L. O. Plantas daninhas em arroz irrigado. In: GOMES, A.S.; MAGALHÃES JÚNIOR, A. M. Arroz irrigado no Sul do Brasil. Brasília: Embrapa Informação Tecnológica, 2004. p. 457-546.

BARIUAN, J. V.; REDDY, K. N.; WILLS, G. D. Glyphosate injury, rainfastness, absorption, and translocation in purple nutsedge (Cyperus rotundus). Weed Technol., v. 13, n. 1, p. 112-119, 1999.
BEYER, E. M. et al. Sulfonylureas. In: KEARNEY, P. C.; KAUFMAN, D. D. (Eds.). Herbicides: chemistry, degradation, and mode of action. New York: Marcel-Dekker, 1988. p. $117-190$.

CONCENÇO, G. et al. Controle de plantas daninhas em arroz irrigado em função de doses de herbicidas pré-emergentes e início da irrigação. Planta Daninha, v. 24, n. 2, p. 303-309, 2006a.

CONCENÇO, G. et al. Efeito de herbicidas aplicados em préemergência e momentos de início da irrigação no crescimento de plantas de arroz. Planta Daninha, v. 24, n. 2, p. 295-301, 2006b.

DEFELICE, M. S. Yellow nutsedge Cyperus esculentus L. Snack food of the gods. Weed Technol., v. 16, n. 4, p. $901-907,2002$.

DORST, D. C.; DOLL, J. D. The allelopathic effect of yellow nutsedge (Cyperus esculentus) on corn (Zea mays) and soybeans (Glycine max). Weed Sci., v. 28, n. 2, p. 229-233, 1980 .

EMPRESA BRASILEIRA DE PESQUISA AGROPECUÁRIA - EMBRAPA. Centro Nacional de Pesquisa Agropecuária de Solos. Sistema brasileiro de classificação de solo. Rio de Janeiro: Embrapa Solos, 2006. $306 \mathrm{p}$.

ERASMO, E. A. L. et al. Efeito da densidade e dos períodos de convivência de Cyperus esculentus na cultura do arroz irrigado. Planta Daninha, v. 21, n. 3, p. 381-386, 2003.

FLECK, N. G. et al. Manejo e controle de plantas daninhas em arroz irrigado. In: VARGAS, L.; ROMAN, E. S. (Eds). Manual de manejo e controle de plantas daninhas. Bento Gonçalves: Embrapa Uva e Vinho, 2004. p. 251-321.

GALON, L. et al. Níveis de dano econômico para decisão de controle de capim-arroz (Echinochloa spp.) em arroz irrigado (Oryza sativa). Planta Daninha, v. 25, n. 4, p. 709-718, 2007.

GOMES, A. S.; PAUletTO, E. A.; PETRINI, J. A. Arroz irrigado: manejo de água. Pelotas: Embrapa Clima Temperado, 1999. 16 p. (Embrapa Clima Temperado. Circular Técnica, 16).

JABUSCH, T. W.; TJEERDEMA, R. S. Partitioning of penoxsulam, a new sulfonamide herbicide. J. Agric. Food Chem., v. 53, n. 18, p. 7179-7183, 2005.

LOPEZ-MARTINEZ, N. et al. Molecular markers indicate intraspecific variation in the control of Echinochloa spp. with quinclorac. Weed Sci., v. 47, n. 3, p. 310-315, 1999.

MACHADO, A. A. et al. Sistema de análises estatísticas para windows - WINSTAT (Versão 2.11). Pelotas: Universidade Federal de Pelotas, 2002. 
NEGBI, M. A. Sweetmeat plant, a perfume plant and their weed relatives: a chapter in the history of Cyperus esculentus L. and C. rotundus L. Econ. Bot., v. 46, n. 1, p. 64-71, 1992.

PINTO, J. J. O. et al. Controle de capim-arroz (Echinochloa spp.) em função de métodos de manejo na cultura do arroz irrigado. Planta Daninha, v. 26, n.4, p. 767-777, 2008.
RAMÍREZ, H. V. et al. Aumento de produtividade através do manejo da água de irrigação na cultura do arroz irrigado. In: CONGRESSO BRASILEIRO DE ARROZ IRRIGADO, 5.; REUNIÃO DA CULTURA DO ARROZ IRRIGADO, 27., 2007, Pelotas. Anais... Pelotas: Embrapa Clima Temperado, 2007. p. 434-435 